\title{
Investigation of Silver Binding to Polyamidoamine (PAMAM) Dendrimers by ESI Tandem Mass Spectrometry
}

\author{
Carolyn L. Mazzitelli and Jennifer S. Brodbelt \\ Department of Chemistry and Biochemistry, The University of Texas at Austin, Austin, Texas, USA
}

\begin{abstract}
Electrospray ionization tandem mass spectrometry (ESI-MS/MS) was used to probe the binding of silver ions and reduced silver species with polyamidoamine generation 1 amineterminated $\left(\mathrm{PAMAMG}_{\mathrm{N} H}\right)$ and generation 2 hydroxyl-terminated (PAMAMG2OH) dendrimers. At $\mathrm{Ag}^{+} /$PAMAMG2OH molar ratios of $\leq 1,1: 1$ complexes are observed, while at ratios $>1,2: 1$ and low abundance 3:1 complexes emerge. Similar results were observed for PAMAMG1NH ${ }_{2}$. The collisional activated dissociation (CAD) patterns of the dendrimer ions are characterized by losses of amidoamine branches resulting largely from hydrogen migration and cleavage reactions. $\mathrm{Ag}^{+} /$dendrimer complexes are characterized by the loss of a dendrimer branch from the complex, with the silver ion remaining bound to a dendrimer fragment. When the $\mathrm{Ag}^{+}$-bound dendrimer complexes are reduced by hydrazine, low abundance complexes, whose $\mathrm{m} / \mathrm{z}$ values are consistent with ones containing zerovalent silver species, are observed in the mass spectra. Complexes with three silver atoms are observed in the spectrum containing PAMAMG1NH ${ }_{2}$, and complexes with four and five silver atoms are observed with PAMAMG2OH. The CAD fragmentation patterns of the complexes formed after the silver reduction are different than those observed for complexes containing one silver ion and are characterized by the ejection of all silver species, possibly as a cluster, leaving the intact dendrimer ion. Experiments with $\mathrm{Cu}^{+}, \mathrm{Cu}^{2+}$, and $\mathrm{Pt}^{2+}$ binding to PAMAMG2OH were also done, but reduced metal clusters were not observed in the mass spectra after the addition of hydrazine. (J Am Soc Mass Spectrom 2006, 17, 676-684) (C) 2006 American Society for Mass Spectrometry
\end{abstract}

$\mathrm{D}$ endrimers comprise a class of highly branched synthetic polymers that have unusual chemical and structural properties [1, 2]. In addition to numerous applications in fields such as medicine, chemistry, materials science, biology, and physics, there is interest in the use of dendrimers as templates for metal nanoparticle synthesis [3, 4]. The ability to synthesize metal nanoparticles with well-defined core sizes has important implications for the study of the sizedependent photochemical, electrochemical, and optical behavior of metal clusters.

Polyamidoamine (PAMAM) dendrimers [5, 6] (Figure 1) constitute one family of dendrimers that have been used to stabilize small metal clusters of defined size. Consisting of an ethylenediamine (EDA) core with repeating amidoamine branches, PAMAM dendrimers have been shown to act as hosts to many metal ions, including $\mathrm{Cu}^{2+}, \mathrm{Pt}^{2+}, \mathrm{Pd}^{2+}, \mathrm{Ni}^{2+}, \mathrm{Fe}^{2+}, \mathrm{Au}^{3+}$, and $\mathrm{Ru}^{3+}$ [7-12]. Upon chemical reduction of the metal ion/ dendrimer complexes, the PAMAM polymer matrix encapsulates and subsequently stabilizes the metal clus-

Published online March 3, 2006

Address reprint requests to Dr. J. S. Brodbelt, Department of Chemistry and Biochemistry, The University of Texas at Austin, 1 University Station A5300, Austin, TX 78712-0165, USA. E-mail: jbrodbelt@mail.utexas.edu ters, thus preventing agglomeration [12]. These intradendrimer metal nanoparticles are soluble and have well defined sizes due to the uniform three-dimensional structure and functional group composition of the dendrimers.

Interest in the formation of intradendrimer metal nanoparticles has stimulated the need for analytical methods that are capable of characterizing the dendrimer host structure and the corresponding metal/ dendrimer complexes. Electrospray ionization mass spectrometry (ESI) [13-17] and matrix assisted laser desorption ionization (MALDI) [18-25] mass spectrometry have been established as powerful techniques for the analysis of dendrimer macromolecules as a result of their ability to gently transfer species from solution to the gas-phase while minimizing the fragmentation of the analyte, allowing for accurate molecular weight measurements and minimal sample consumption. Many of the past mass spectrometric studies related to PAMAM dendrimers have focused on using ESI-MS to evaluate the molecular weight [26-28] and gas-phase fragmentation of PAMAM dendrimers [29] in the absence of metal ions or nanoparticles. These studies describe mass spectrometric techniques that provide useful information for improving synthetic strategies of dendrimers. For example, Tolic et al. utilized Fourier 
(a)

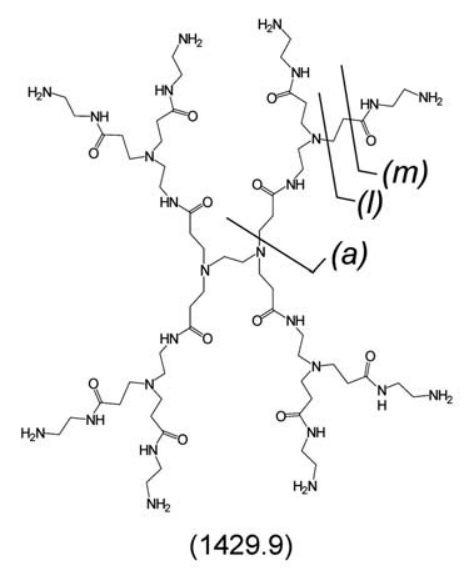

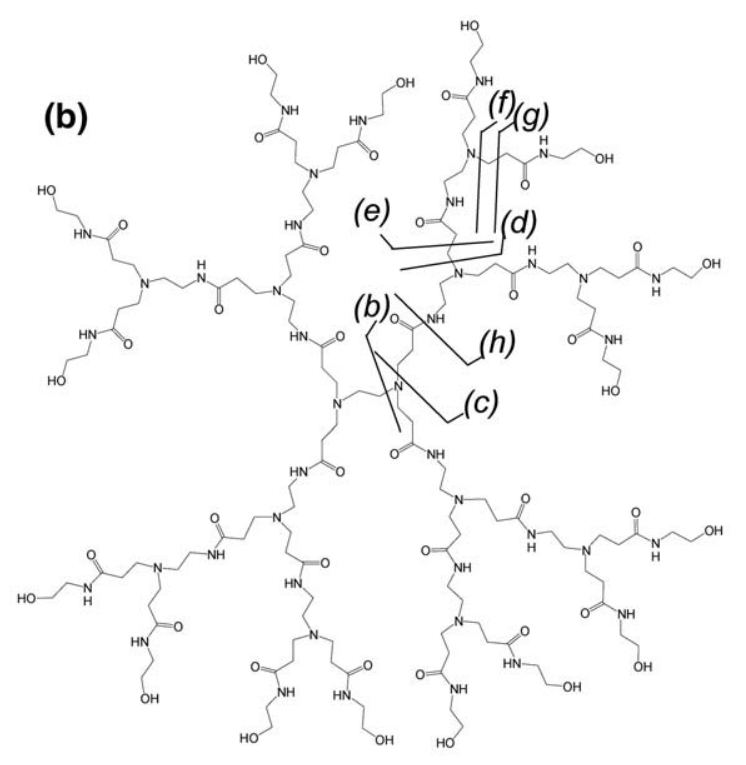

(3271.9)

Figure 1. Structures of (a) polyamidoamine generation 1 amine-terminated $\left(\mathrm{PAMAMG}_{\mathrm{N}} \mathrm{NH}_{2}\right)$ and generation (b) hydroxy-terminated generation 2 (PAMAMG2OH) dendrimers. Compound molecular weights in Da are given in parenthesis. Dendrimer fragments lost due to defects or CAD are indicated.

transform ion cyclotron resonance mass spectrometry (FT-ICR MS) to investigate the polydispersity of PAMAM dendrimers [28], while collisional activated dissociation and ion/ion reactions were used by He and McLuckey to study the dissociation behavior of halfgeneration PAMAM dendrimers and determine the structures of imperfect dendrimer molecules [29]. MALDI- TOF mass spectrometry has also been used to determine structural deviations in PAMAM dendrimers $[25,31]$.

Mass spectrometry has also been used as a tool to study metal ion/dendrimer complexes. The characterization of these complexes is a key aspect in understanding the relationship between the dendrimer structure, the dendrimer/metal ion complex, and the resulting dendrimer-encapsulated metal nanoparticles. MALDI-TOF mass spectrometry was used to examine the binding of $\mathrm{Cu}^{2+}$ to hydroxyl terminated dendrimers [30], and in a recent study, we examined the binding of silver ions to G1 PAMAMNH ${ }_{2}$ dendrimers using electrochemical, spectroscopic, and mass spectrometric techniques [32]. ESI-MS was used to determine $\mathrm{Ag}^{+} /$ PAMAM dendrimer binding stoichiometries at equimolar concentrations [32].

Our current study serves as a continuation of our initial ESI-MS experiments of silver/dendrimer complexes [32]. ESI tandem mass spectrometry is employed to characterize the binding stoichiometry of complexes formed between silver ions and polyamidoamine generation 1 amine terminated (PAMAMG1NH ${ }_{2}$ ) and generation 2 hydroxyl terminated (PAMAMG2OH) dendrimers (see Figure 1) at different silver/dendrimer molar ratios. Low generation dendrimers are used in this study to develop a framework for analyzing larger, more complex dendrimer molecules by ESI-MS. Collisional activated dissociation (CAD) fragmentation patterns of the PAMAM dendrimer complexes are also evaluated to gain structural information about the complexes. Additionally, we report evidence for the formation of silver clusters after the reduction of solutions containing $\mathrm{Ag}^{+} /$dendrimer complexes.

\section{Experimental}

Materials

Amine-terminated generation 1 polyamidoamine (PAMAM) and hydroxyl-terminated generation 2 PAMAM dendrimers were purchased from Dendritech, Inc. (Midland, MI) or Aldrich Chemical Co. (Milwaukee, WI), and were used without further purification. Anhydrous hydrazine and the metal salts $\mathrm{AgNO}_{3}$, $\mathrm{CuBr}_{2}, \mathrm{CuCl}$, and $\mathrm{PtCl}_{2}$ were purchased from Aldrich Chemical Co. and were used as received. All other chemicals were reagent grade and were used without further purification.

\section{Instrumentation and Procedures}

Stock solutions of PAMAMG1NH ${ }_{2}$ and PAMAMG2OH were prepared at $1 \mathrm{mM}$ in methanol. The metal salt stock solutions were also prepared at $1 \mathrm{mM}$ in water. Analytical solutions containing a mixture of dendrimer and metal salt were prepared at dendrimer/silver molar ratios ranging from $1: 4$ to $4: 1$ in $50 \%$ methanol/ water.

To transform the dendrimer bound $\mathrm{Ag}^{+}$to the zerovalent silver species, hydrazine was added at concen- 
trations in excess of the silver ion. Solutions containing $0.12 \mathrm{mM}$ PAMAMG1NH $\mathrm{N}_{2}$ and $0.24 \mathrm{mM} \mathrm{AgNO}_{3}$ were prepared in water to maintain conditions similar to those used in the spectroscopic studies. Excess $\mathrm{AgNO}_{3}$ was used to promote the formation of the silver/ dendrimer complexes. After allowing the solutions to equilibrate, a portion of this solution was diluted with water and methanol to micromolar concentrations suitable for ESI-MS analysis (i.e., $\sim 10 \mu \mathrm{M}$ dendrimer and 20 $\mu \mathrm{M} \mathrm{AgNO}_{3}$ ). Next, $0.96 \mathrm{mM}$ hydrazine was added to the initial silver/dendrimer solution. The high ratio of hydrazine to silver was used to ensure more complete reduction of the silver ions present in the solution. Upon reduction, no precipitate was observed, indicating that the reduced silver species remained soluble. After $30 \mathrm{~min}$ equilibration time, the solution was diluted and analyzed by ESI-MS.

The same procedure was followed to reduce the $\mathrm{Ag}^{+}, \mathrm{Cu}^{+}$, or $\mathrm{Cu}^{2+}$ bound to PAMAMG2OH, except the stock solutions contained PAMAMG2OH at $0.12 \mathrm{mM}$ and metal salt at $0.48 \mathrm{mM}$. Hydrazine was added at 0.96 $\mathrm{mM}$ so that after dilution with water and methanol the solutions contained $10 \mu \mathrm{M}$ dendrimer, $40 \mu \mathrm{M}$ metal salt, and $80 \mu \mathrm{M}$ hydrazine.

A Harvard syringe pump (Holliston, MA) set at a flow rate of $3 \mu \mathrm{L} / \mathrm{min}$ was used to directly infuse the samples into a ThermoFinnigan LCQ Duo quadrupole ion trap mass spectrometer (San Jose, CA). The ESI source was operated in positive ion mode with an electrospray voltage of $4.0 \mathrm{kV}$ and a heated capillary temperature ranging from 125 to $175^{\circ} \mathrm{C}$. Sheath and auxiliary gas flow rates of 30 and 10 arbitrary units, respectively, were used to aid in desolvation. The base pressure of the trap was $\sim 1 \times 10^{-5}$ torr. Selected dendrimer complex ions were subjected to collisional activated dissociation (CAD) experiments by isolating the precursor ion in the trap using resonance ejection, followed by increasing the collision energy applied to the trap to cause ion fragmentation. An activation time of $30 \mathrm{~ms}$ was used for all CAD experiments. All mass spectra were acquired by summing 300 scans with an ionization time of 50 to $100 \mathrm{~ms}$.

High-resolution mass spectrometry experiments were performed using a Q-TOF Premier (Waters) equipped with an ESI source operated in the positive ion mode. To obtain high mass accuracy measurements, lock mass injection was employed using leucine enkephalin as the calibrant. The analyte injection volume was $5 \mu \mathrm{L}$. An ESI voltage of $3.5 \mathrm{kV}$ and a cone voltage of $40 \mathrm{~V}$ were used. The source temperature was $160^{\circ} \mathrm{C}$; the desolvation temperature was $70^{\circ} \mathrm{C}$.

\section{Results and Discussion}

\section{Analysis of Silver Ion Complexes by ESI-MS}

The ESI mass spectrum of a solution containing equimolar concentrations of $\mathrm{Ag}^{+}$and PAMAMG1NH was reported in a previous study [32], with results indicating that the complexes containing a 1:1 binding stoichiometry were the major silver-containing species. In this study, we examine solutions containing different molar ratios of $\mathrm{Ag}^{+} / \mathrm{PAMAMG1NH}_{2}$ (spectra not shown). At $\mathrm{Ag}^{+} / \mathrm{PAMAMG1NH}_{2}$ molar ratios of 1:2 and 1:4, complexes with 1:1 binding stoichiometries are detected, but with lower relative abundances than observed for complexes present in an equimolar $\mathrm{Ag}^{+} /$ $\mathrm{PAMAMG1NH}_{2}$ solution. As the molar ratio is increased above 1:1, ions corresponding to a 2:1 binding stoichiometry are detected in addition to 3:1 complexes of lower abundance that emerge when there is 4 -fold excess of $\mathrm{Ag}^{+}$. These results are on par with previously reported electrochemical studies of $\mathrm{Ag}^{+}$binding to PAMAMG1NH ${ }_{2}$ that found the 1:1 stoichiometry to be present in solutions containing a mole ratio of $\mathrm{AgNO}_{3}$ to dendrimer of $\leq 1$, while 2:1 complexes can form when the mole ratio is $>1$ [32].

The silver ion binding to a larger dendrimer, the hydroxyl-terminated generation 2 PAMAM dendrimer, was also evaluated. The ESI mass spectrum of a solution containing $10 \mu \mathrm{M}$ PAMAMG2OH in 1:1 water/methanol is shown in Figure 2a. The $2+$ and $3+$ charge state ions of the intact dendrimer are present, in addition to abundant ions corresponding to the dendrimer with one to two sodium ions incorporated. The sodium ions are present as a contaminant in solution. In addition to ions corresponding to the intact dendrimer, products resulting from dendrimer defects, such as the loss of an amidoamine branch are also present. The most abundant incomplete dendrimer ion is formed upon the loss of a " $c$ " moiety (illustrated in Figure 1b). There are additional ions that correspond to losses of one to four " $f$ " groups in the $\mathrm{m} / \mathrm{z}$ range of 1400 to 1600 . Due to the complexity of the dendrimer mass spectra, only ions containing the intact dendrimers are labeled in Figure 2. A spectrum showing the full assignments of the PAMAMG2OH dendrimer and defect ions is included in Supplementary Material section Figure S-1 (which can be found in the electronic version of this article). Because the abundance of the dendrimer defect species do not change with the severity of the ESI conditions and similar defects have been observed in past MALDI $[30,31]$ and ESI [28] studies, we speculate that these defects are present in the original dendrimer samples and do not arise from the ESI process. It has been previously shown that the types of defects observed in Figure 2 result from the retro-Michael decomposition reactions that occur in the dendrimer solutions [33].

Silver ion/dendrimer complexes were observed in the ESI mass spectrum of a sample containing $20 \mu \mathrm{M}$ $\mathrm{AgNO}_{3}$ and $10 \mu \mathrm{M}$ PAMAMG2OH (Figure 2b). The complexes retain a dominant $1: 1 \mathrm{Ag}^{+} / \mathrm{PAMAMG} 2 \mathrm{OH}$ stoichiometry. Some complexes contained a silver ion in addition to a sodium ion. A complex formed between a silver ion and a dendrimer defect ion, [PAMAMG2OH $\left.+\mathrm{Na}^{+}-c+\mathrm{Ag}^{+}\right]^{2+}$ is also observed. Electrochemical studies of the $\mathrm{Ag}^{+} /$PAMAMG2OH indicate that the 1:1 complex was the major silver containing species in 



Figure 2. ESI mass spectra for complexes containing $10 \mu \mathrm{m}$ PAMAMG2OH (a) alone and (b) with 20 $\mu \mathrm{m} \mathrm{AgNO}_{3}$. Dendrimer is abbreviated as "ddm" in the labels.

samples containing roughly equimolar concentration of silver and dendrimer [32]. These results are confirmed in the mass spectra of the $\mathrm{Ag}^{+} / \mathrm{PAMAMG} 2 \mathrm{OH}$ solutions.

To examine how the complexation process and stoichiometries change as the $\mathrm{Ag}^{+} /$PAMAMG2OH molar ratio is varied, a series of solutions with silver/PAMAMG2OH molar ratios of $10 \mu \mathrm{M}: 40 \mu \mathrm{M}$, $10 \mu \mathrm{M}: 20 \mu \mathrm{M}, 10 \mu \mathrm{M}: 10 \mu \mathrm{M}, 20 \mu \mathrm{M}: 10 \mu \mathrm{M}$, and 40 $\mu \mathrm{M}: 10 \mu \mathrm{M}$ were analyzed by ESI-MS as shown in the Figure S-2. Even when the $\mathrm{Ag}^{+} / \mathrm{PAMAMG2OH}$ molar ratio is less than $1: 1$, complexes with a $1: 1 \mathrm{Ag}^{+} /$ dendrimer stoichiometry are observed in the mass spectra (Figure S-2A and S-2B). As the silver/dendrimer molar ratio is increased to 2:1 (Figure S-2D) and 4:1 (Figure S-2E), complexes with a 2:1 binding stoichiometry are detected in addition to the $1: 1$ complexes. The changes in the $\mathrm{Ag}^{+} /$dendrimer binding stoichiometries reflected in Figure S-2 are consistent with the results of the previous electrochemical study of $\mathrm{Ag}^{+}$binding to PAMAMG2OH [32]. The results of this study found that 1:1 complexes are dominant in solutions with $\mathrm{Ag}^{+} /$PAMAMG2OH molar rations of $\leq 1$, while 2:1 complexes form when the molar ratio is $>1$. Similar changes in complexation as a function of concentration are reflected in the ESI mass spectra shown in Figure S-2

The $\mathrm{m} / \mathrm{z}$ values of some of the $\mathrm{Ag}^{+} / \mathrm{PAMAMG} 2 \mathrm{OH}$ complexes were similar to those of dendrimer fragments bound to silver, so high-resolution mass spectrometric experiments were performed on a Q-TOF instrument with an ESI source to confirm the ion assignments (spectra not shown). The full scan spectra of solutions containing PAMAMG2OH at $10 \mu \mathrm{M}$ and $\mathrm{AgNO}_{3}$ at 40 $\mu \mathrm{M}$ shows an ion present at $m / z 1689.4801$. The chemical composition of this ion was calculated to be $\mathrm{C}_{142} \mathrm{H}_{273} \mathrm{~N}_{42} \mathrm{O}_{44} \mathrm{Ag}$ with $1.7 \mathrm{ppm}$ accuracy. This matches the molecular formula of the $\left[\mathrm{ddm}+\mathrm{Ag}^{+}+\right.$ $\left.\mathrm{H}^{+}\right]^{2+}$ complex. An ion at $m / z 1126.3158$ was confirmed to be the $\left[\mathrm{ddm}+\mathrm{Ag}^{+}+2 \mathrm{x} \mathrm{H}^{+}\right]^{3+}$ complex $\left(\mathrm{C}_{142} \mathrm{H}_{274} \mathrm{~N}_{42} \mathrm{O}_{44} \mathrm{Ag}\right)$ with $-2.2 \mathrm{ppm}$ accuracy. Another complex was present at $\mathrm{m} / \mathrm{z} 1160.9292$ and was consistent with a chemical composition of $\mathrm{C}_{142} \mathrm{H}_{273} \mathrm{~N}_{42} \mathrm{O}_{44} \mathrm{Ag}_{2}$ (11.8 ppm accuracy), corresponding to the [ddm $+2 \times$ $\left.\mathrm{Ag}^{+}+\mathrm{H}^{+}\right]^{3+}$ complex. We attribute the higher error in the mass accuracy of this last ion to its low abundance in the Q-TOF spectrum because of a different ESI source. These ion peaks fit the isotope patterns that would be expected for silver/dendrimer complexes, further verifying the assignments.

\section{ESI-MS/MS of Complexes Containing $\mathrm{PAMAMG}_{\mathrm{NHH}}$ and PAMAMG2OH}

CAD experiments were undertaken to characterize the protonated dendrimers and silver ion/dendrimer complexes. Protonated PAMAMG1NH $\mathrm{P}_{2}$ in the $1+$ (Figure $3 a)$ or $2+$ (Figure $3 b$ ) charge states dissociates via loss of ammonia, in addition to cleavages of amidoamine branches as indicated by the losses of $a$ or $l$ moieties (see Figure 1a for a summary of these processes and Table 1 for the masses of the fragments). These fragmentation patterns result from hydrogen migration and cleavage reactions, and examples of these pathways that are consistent with the products are shown in Scheme $\mathbf{1}$. Our results indicate that these reactions occur most commonly at the most exterior tertiary amine to produce a loss of $114 \mathrm{Da}$ ( $l$ moiety) and at the interior tertiary amine via the loss of $342 \mathrm{Da}$ (a moiety).

The CAD spectra of the $\left[\text { PAMAMG1NH }{ }_{2}+\mathrm{Ag}^{+}\right]^{+}$ and [PAMAMG1NH $\left.H_{2}+\mathrm{Ag}^{+}+\mathrm{H}^{+}\right]^{2+}$ complexes shown in Figure $3 c$ and d demonstrate that similar dissociation pathways are followed for these complexes. In addition to the cleavage of $a$ and $l$ groups, the loss of an $m$ moiety is also observed which may be influenced by the presence of the silver ion. One proposed binding site of the silver ion to the dendrimer 



Figure 3. CAD spectra for complexes PAMAMG1NH $\mathrm{P}_{2}$ (a) CAD of $\left[\mathrm{ddm}+\mathrm{H}^{+}\right]^{+}$, (b) CAD of $[\mathrm{ddm}$ $\left.+2 \times \mathrm{H}^{+}\right]^{+2}$, (c) CAD of $\left[\mathrm{ddm}+\mathrm{Ag}^{+}\right]^{+}$, and (d) CAD of $\left[\mathrm{ddm}+\mathrm{Ag}^{+}+\mathrm{H}^{+}\right]^{+2}$. Dendrimer is abbreviated as "ddm" in the labels. The precursor ion is labeled with an asterisk.

involves the tertiary amine groups, which could promote the loss of the $m$ branch. In general, the loss of silver alone is never observed in the CAD spectra of the $\mathrm{Ag}^{+} / \mathrm{PAMAMG1NH}_{2}$ complexes, indicating it remains bound to a portion of the dendrimer upon collisional activation. Figure 3 also reveals that the loss of $\mathrm{NH}_{3}$ is observed in the CAD spectra of $\left[\mathrm{ddm}+\mathrm{H}^{+}\right]^{+}$(Figure $3 a),\left[\mathrm{ddm}+2 \times \mathrm{H}^{+}\right]^{2+}$ (Figure $3 \mathrm{~b}$ ), and $\left[\mathrm{ddm}+\mathrm{Ag}^{+}+\right.$ $\left.\mathrm{H}^{+}\right]^{2+}$ (Figure 3d).

Protonated and silver-cationized PAMAMG2OH complexes were also subjected to CAD. Fragments that are lost upon collisional activation are shown in Figure $1 \mathrm{~b}$ with the corresponding masses given in Table 1, and the structures of the fragments are consistent with the formulas obtained from the mass spectra. The CAD spectrum of PAMAMG2OH in the $2+$ charge state (Figure 4a) shows a greater variety of fragmentation routes than observed for the analogous PAMAMG1NH ${ }_{2}$ complexes. The losses of $f$ and $d$ fragments, which are similar to the $l$ and $a$ losses observed for PAMAMG1NH ${ }_{2}$ (Figure 3), are present in Figure 4a but the abundances of these fragments are lower than the product ions formed after losses of $g$ and $e$. The formation of $c$ ions is also indicated in the CAD spectrum.

Table 1. Mass (in Da) of dendrimer fragments that are lost from the dendrimer due to incomplete synthesis and spontaneous decomposition reactions in solution, or lost upon collisional activated dissocation (CAD)

\begin{tabular}{cccr}
\hline $\begin{array}{c}\text { PAMAMG1NH } \\
\text { fragments }\end{array}$ & Mass & $\begin{array}{c}\text { PAMAMG2OH } \\
\text { fragments }\end{array}$ & Mass \\
\hline \hline$a$ & 342 & $b$ & 1622 \\
$l$ & 114 & $c$ & 802 \\
$m$ & 86 & $d$ & 344 \\
& & $e$ & 330 \\
& & $f$ & 115 \\
& & $g$ & 101 \\
& & $h$ & 748 \\
\hline
\end{tabular}

The same losses that were observed from the $\left[\text { PAMAMG2OH }+2 \times \mathrm{H}^{+}\right]^{2+}$ species $(d, e, f$, and $g$ pathways) are also observed for the [PAMAMG2OH + $\left.\mathrm{H}^{+}+\mathrm{Ag}^{+}\right]^{2+}$ complex, in addition to the formation of the $[c+\mathrm{H}]^{+},\left[c+\mathrm{Ag}^{+}\right]^{+},\left[b+\mathrm{Ag}^{+}\right]^{+}$, and $\left[h+\mathrm{Ag}^{+}\right]^{+}$ ions as shown in the spectrum in Figure $4 \mathrm{~b}$. While these product ions indicate that $\mathrm{Ag}^{+}$remains bound to $b, c$, and $h$ fragments, there is no evidence that the silver ions are retained by the $d, e, f$, and $g$ fragments that are lost, suggesting that the silver ion is bound to the dendrimer via one of the four tertiary amines closest to the initiator core of the dendrimer. These results agree with past studies that suggest that $\mathrm{OH}$-terminated dendrimers form metal ion complexes with interior tertiary amines [3].

\section{Hydrazine Reduction of $\mathrm{Ag}^{+} / \mathrm{PAMAMG1NH}$ and $\mathrm{Ag}^{+} / \mathrm{PAMAMG2OH}$ Complexes}

Previous UV-Vis spectroscopic studies suggest that upon chemical reduction of $\mathrm{Ag}^{+}-\mathrm{PAMAMG1NH}_{2}$ complexes, small zerovalent silver clusters and larger nanoparticles are formed simultaneously [32]. While the threshold size of the silver clusters and nanoparticles can be determined by the UV-Vis spectra, the number of reduced silver atoms in each cluster remains unknown. ESI-MS experiments were undertaken on solutions containing the reduced silver species to determine if clusters (containing 10 silver atoms or fewer) bound to the dendrimer can be observed in the mass spectra.

A typical mass spectrum resulting from a solution containing $10 \mu \mathrm{M}$ PAMAMG1NH ${ }_{2}$ and $20 \mu \mathrm{M} \mathrm{AgNO}_{3}$ (prepared by diluting a portion of a stock solution containing $0.12 \mathrm{mM}$ PAMAMG1NH $\mathrm{N}_{2}$ and $0.24 \mathrm{mM}$ $\mathrm{AgNO}_{3}$ ) is shown in Figure 5a. For visual simplicity, only the ions containing intact dendrimers are labeled in Figure 5a, however a spectrum showing the assignment of all ions is included in Figure S-3. As expected, 


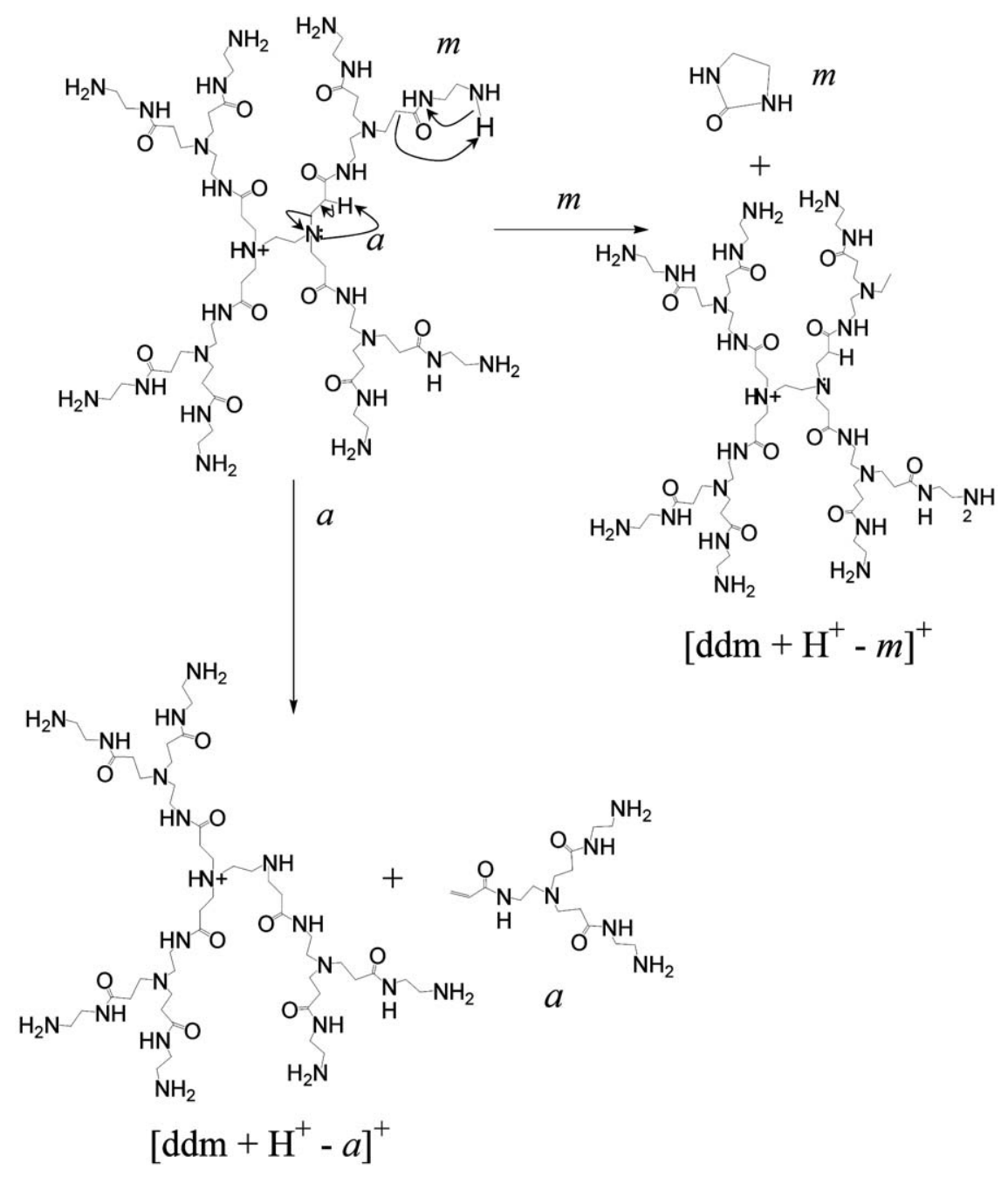

Scheme 1. A pathway showing the hydrogen migration and cleavage reaction leading to the loss of " $a$ " and " $m$ " moieties.
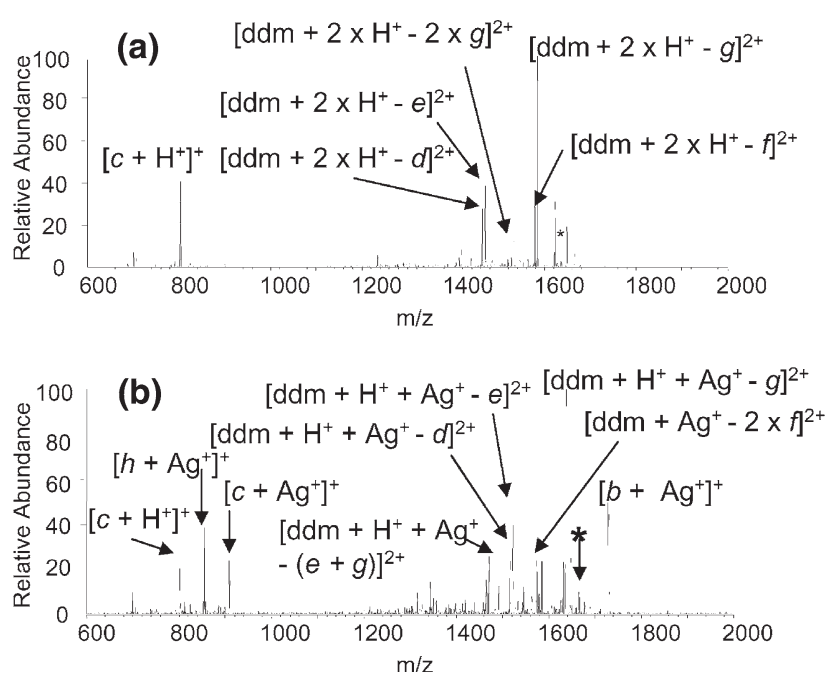

Figure 4. CAD spectra for complexes PAMAMG2OH: (a) CAD of $\left[\mathrm{ddm}+2 \times \mathrm{H}^{+}\right]^{+2}$ and (b) CAD of $\left[\mathrm{ddm}+\mathrm{H}^{+}+\mathrm{Ag}^{+}\right]^{+2}$. Dendrimer is abbreviated as "ddm" in the labels. The precursor ion is labeled with an asterisk. silver ion-dendrimer complexes with 1:1 and 2:1 binding stoichiometries are present in the mass spectrum. The ESI mass spectrum of the solution after the addition of $0.96 \mathrm{mM}$ hydrazine to the stock silver/dendrimer solution, followed by dilution for ESI-MS analysis (Figure $5 \mathrm{~b}$ ) shows several changes in ion abundances and the appearance of several new product ions, including a particularly notable one at $m / z 887$. The $m / z$ of this latter ion is consistent with a dendrimer complex containing three silver atoms and one sodium atom in the +2 charge state. The spectral region around the new peak $(\mathrm{m} / \mathrm{z} 800$ to 920$)$ is enlarged (see inset of Figure 5) to highlight the emergence of this new peak, which is evidence for a complex that contains zerovalent silver species via a small cluster of three silver atoms formed upon the hydrazine reduction. While the abundance of this new complex is low, the efficiency of formation of complexes containing silver clusters in bulk solution is expected to be low as well. The incorporation of the sodium in the complexes suggests that the sodium ion 


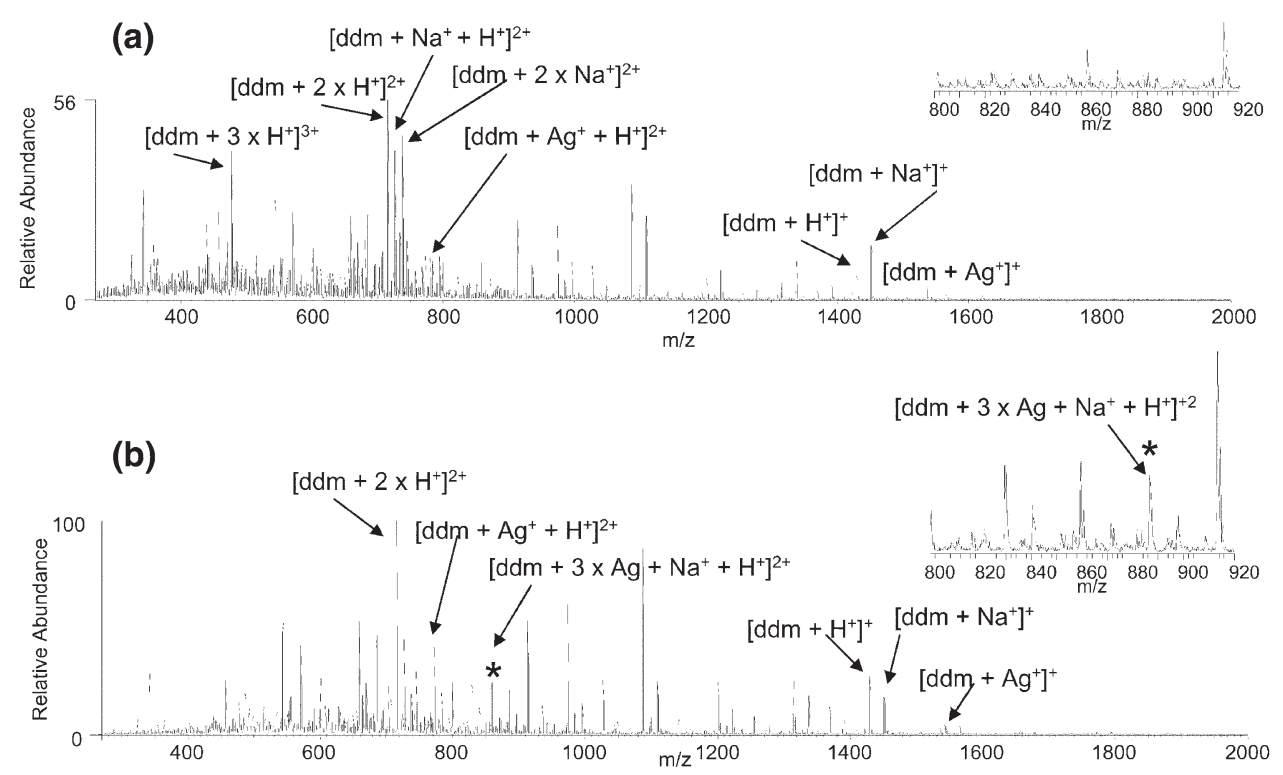

Figure 5. ESI mass spectra for complexes containing $10 \mu \mathrm{M} \mathrm{PAMAMG1NH}$ with $20 \mu \mathrm{M} \mathrm{AgNO}_{3}$; (a) before hydrazine reduction and (b) after addition of $80 \mu \mathrm{M}$ hydrazine. For visual simplicity, only the ions containing intact dendrimers are labeled in (a) and (b).

plays a role in aiding the ionization of a complex containing the reduced silver.

The reduction was also performed using lower molar ratios of silver. Samples containing an initial concentration of $0.1 \mathrm{mM}$ PAMAMG1NH${ }_{2}, 0.024 \mathrm{mM} \mathrm{AgNO}_{3}$, and $0.1 \mathrm{mM}$ hydrazine were diluted to $10 \mu \mathrm{M}$ dendrimer, $2.4 \mu \mathrm{M} \mathrm{AgNO} 2$ and $10 \mu \mathrm{M}$ hydrazine. The ESI mass spectra (not shown) indicate that the complex at $\mathrm{m} / \mathrm{z} 887$ was present after the hydrazine reduction, but with lower relative abundance than it was when higher molar ratios of $\mathrm{AgNO}_{3}$ was used (Figure 5b).

The CAD spectrum of the $\left[\mathrm{ddm}+3 \times \mathrm{Ag}+\mathrm{Na}^{+}+\right.$ $\left.\mathrm{H}^{+}\right]^{2+}$ complex demonstrates that the complex dissociates via the loss of an amine group and an amidoamine branch, similar to the behavior observed for the $\mathrm{Ag}^{+} /$ $\mathrm{PAMAMG}_{\mathrm{NH}} \mathrm{H}_{2}$ complexes (Figure S-4). However, there is an additional product ion that corresponds to the $1+$ charge state of the intact dendrimer, without bound silver or sodium. This product indicates that all three silver atoms and the sodium atom are ejected, leaving the intact dendrimer. This type of fragmentation route was never observed in the CAD spectra of the $\mathrm{Ag}^{+} /$dendrimer complexes. Furthermore, the silver and sodium species are ejected with a single positive charge, consistent with reduction of at least some of the silver atoms to the zerovalent state. These results suggest that a dendrimer complex containing three silver atoms is formed after hydrazine reduction of a solution containing $\mathrm{Ag}^{+}$and PAMAMG1NH${ }_{2}$.

UV-Vis spectroscopic experiments suggest that the formation of small silver clusters is favored by the $\mathrm{Ag}^{+}$-PAMAMG2OH complex because $\mathrm{Ag}^{+}$is thought to bind to the dendrimer via the interior tertiary amines more strongly than to the terminal hydroxy groups, thus promoting the formation of intradendrimer clus- ters that are less prone to agglomeration to form larger nanoparticles [32]. Figure 6 shows the full mass spectra of solutions containing $10 \mu \mathrm{M}$ PAMAMG2OH and 40 $\mu \mathrm{M} \mathrm{AgNO}$ before (Figure 6a) and after (Figure 6b) the addition of hydrazine. There are some considerable changes to the mass spectrum of the sample after the hydrazine reduction; most noticeably, the abundance of the $\mathrm{Ag}^{+}$-PAMAMG2OH complexes is significantly decreased. This may be due to the formation of large silver clusters stemming from reduction and agglomeration of the silver species that are not observable by ESI-MS. In addition to the decreased abundance of the silver ion/ dendrimer complexes, low abundance ions emerge in the $1800-2000 \mathrm{~m} / \mathrm{z}$ range. This spectral region is enlarged in Figure $6 \mathrm{a}$ and $\mathrm{b}$ for closer examination. Ions are found at $\mathrm{m} / \mathrm{z} 1916$ and 1876, consistent with $\mathrm{m} / \mathrm{z}$ values of complexes of the type [PAMAMG2OH $+5 \times$ $\left.\mathrm{Ag}+\mathrm{Na}^{+}+\mathrm{H}^{+}\right]^{2+}$ and [PAMAMG2OH $+4 \times \mathrm{Ag}+$ $\left.2 \times \mathrm{Na}^{+}\right]^{2+}$, suggesting that the complexes contain reduced silver ion clusters. The sodium ions are likely present in the complexes to aid in cationizing of the complexes containing the reduced silver species, as observed for the complexes containing PAMAMG1NH (discussed above).

The CAD spectrum of the [PAMAMG2OH $+5 \times \mathrm{Ag}$ $\left.+\mathrm{Na}^{+}+\mathrm{H}^{+}\right]^{2+}$ complex (Figure S-5A) is considerably different than the CAD spectra of the $\mathrm{Ag}^{+} /$ PAMAMG2OH complexes (Figure 4). The primary product ion is the intact, bare dendrimer ion in the $2+$ charge state. The formation of this ion suggests that all of the silver and sodium atoms are ejected upon collisional activation. Furthermore, there is no shift in the charge state of the product ion, indicating that the silver/sodium atoms are ejected as neutral species. A similar fragmentation pattern was observed for the 


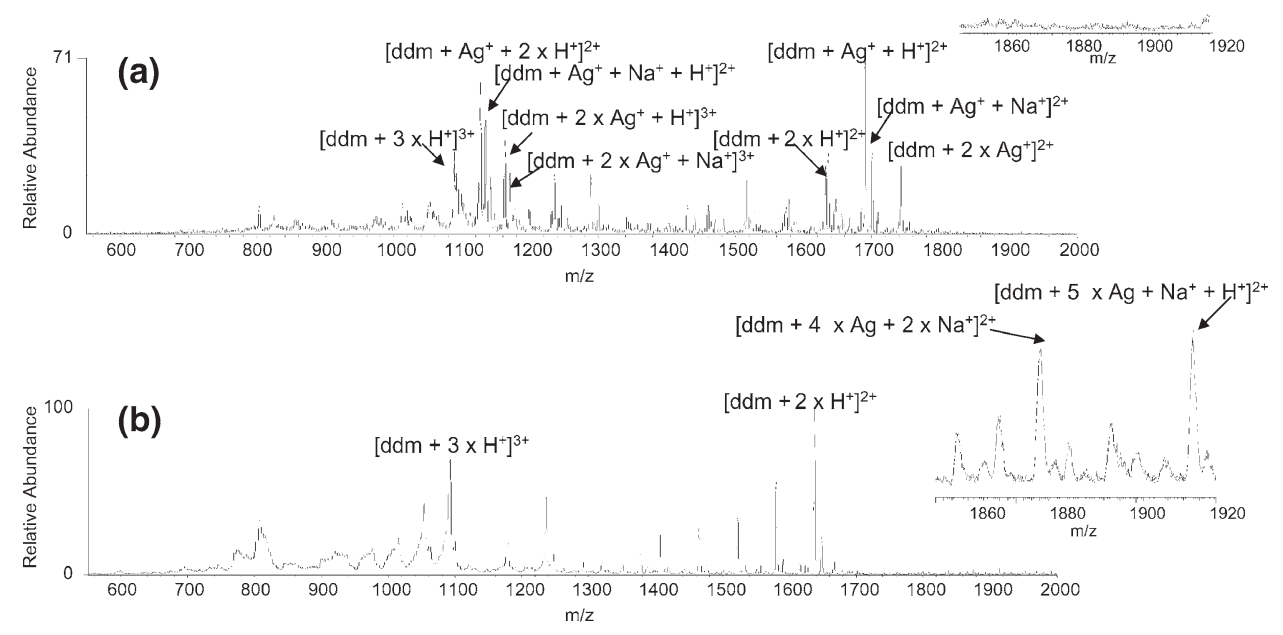

Figure 6. ESI mass spectra for complexes containing $10 \mu \mathrm{M}$ PAMAMG2OH with $40 \mu \mathrm{M} \mathrm{AgNO}_{3}$; (a) before hydrazine reduction and (b) after addition of $80 \mu \mathrm{M}$ hydrazine. For visual simplicity, only the ions containing intact dendrimers are labeled in (a) and (b).

$\left[\text { PAMAMG2OH }+4 \times \mathrm{Ag}+2 \times \mathrm{Na}^{+}\right]^{2+}$ complex (Figure S-5B). The $2+$ charge state of the intact dendrimer is formed after the ejection of all silver and sodium species. In addition, an ion is formed after the loss of an $f$ branch from the bare dendrimer. In contrast, the CAD spectra of the $\mathrm{Ag}^{+} / \mathrm{PAMAMG} 2 \mathrm{OH}$ complexes indicate the silver ion remains bound to fragments of the dendrimer upon dissociation.

\section{Hydrazine Reduction of PAMAMG1NH $\mathrm{NH}_{2}$ and PAMAMG2OH}

Hydrazine reductions of solutions containing the dendrimers without $\mathrm{AgNO}_{3}$ were performed to assess the effect of the reduction process on the metal-free dendrimers. The ESI mass spectra of the samples containing $10 \mu \mathrm{M}$ PAMAMG1NH $\mathrm{N}_{2}$ and $10 \mu \mathrm{M}$ PAMAMG2OH before and after the addition of $80 \mu \mathrm{M}$ hydrazine (spectra not shown) indicate that there are no changes to the spectra upon the addition of hydrazine. The ions produced upon the reduction of the $\mathrm{Ag}^{+} /$dendrimer solutions are not observed after the hydrazine reduction of solutions containing the dendrimers without silver.

\section{PAMAMG2OH Binding to Other Metals}

To further demonstrate the scope of this technique, solutions containing PAMAMG2OH with $\mathrm{Cu}^{2+}, \mathrm{Cu}^{+}$, and $\mathrm{Pt}^{2+}$ were also analyzed by ESI-MS using the same instrument and solution conditions used in the experiments with $\mathrm{Ag}^{+}$(spectra not shown). At equimolar concentrations $(10 \mu \mathrm{M})$ of PAMAMG2OH and $\mathrm{Cu}^{2+}$, ions corresponding to the [PAMAMG2OH $\left.+\mathrm{Cu}^{2+}\right]^{2+}$ and $\left[\mathrm{PAMAMG} 2 \mathrm{OH}+2 \times \mathrm{Cu}^{2+}-2 \times \mathrm{H}^{+}\right]^{2+}$ complexes are present in the full scan mass spectrum. When the $\mathrm{Cu}^{2+} / \mathrm{PAMAMG} 2 \mathrm{OH}$ molar ratio is increased to 40 $\mu \mathrm{M}: 10 \mu \mathrm{M}$, the abundance of the [PAMAMG2OH +2 $\left.\times \mathrm{Cu}^{2+}-2 \times \mathrm{H}^{+}\right]^{2+}$ significantly increases, and the $\left[\text { PAMAMG2OH }+3 \times \mathrm{Cu}^{2+}-4 \times \mathrm{H}^{+}\right]^{2+}$ ion emerges. $\mathrm{Cu}^{+}$was also found to form complexes with PAMAMG2OH, however the $\mathrm{Cu}^{+} /$PAMAMG2OH binding stoichiometries were lower than those observed with $\mathrm{Cu}^{2+}$. As the $\mathrm{Cu}^{+} /$PAMAMG2OH molar ratio is increased from $10 \mu \mathrm{M}: 10 \mu \mathrm{M}$ to $20 \mu \mathrm{M}$ : $10 \mu \mathrm{M}$, the $\left[\mathrm{PAMAMG} 2 \mathrm{OH}+\mathrm{Cu}^{+}+\mathrm{H}^{+}\right]^{2+}$ is present but with low relative abundance. When the concentration of $\mathrm{Cu}^{+}$ is raised to $40 \mu \mathrm{M}$, the abundance of the [PAMAMG2OH $\left.+\mathrm{Cu}^{+}+\mathrm{H}^{+}\right]^{2+}$ increases, and a low abundance 2:1 ion is also present. No metal-containing complexes were observed in the spectra of solutions containing $\mathrm{Pt}^{2+}$ with PAMAMG2OH.

The mass spectra for a solution containing $\mathrm{Cu}^{2+}$ / PAMAMG2OH after the addition of hydrazine were also obtained (spectra not shown) using the same procedure discussed above for experiments involving $\mathrm{Ag}^{+}$. The most dramatic change to the spectra was the diminishment of the $\mathrm{Cu}^{2+} / \mathrm{PAMAMG} 2 \mathrm{OH}$ complexes as was observed for the silver complexes. Unlike the experiments with $\mathrm{Ag}(\mathrm{I})$, new species containing copper clusters were not detected. Similar results were observed for samples containing $\mathrm{Cu}^{2+}$. While these results demonstrate that other types of metal ion/dendrimer complexes can be observed by ESI-MS, only those complexes containing $\mathrm{Ag}(\mathrm{I})$ resulted in the formation of reduced metal clusters.

\section{Conclusions}

ESI mass spectrometry was used to examine the binding of silver ions and reduced silver species to PAMAM dendrimers. At equimolar concentrations of PAMAMG2OH and $\mathrm{AgNO}_{3}$, complexes with $\mathrm{Ag}^{+} /$ dendrimer binding stoichiometries of 1:1 are present in the ESI mass spectra. The 1:1 complexes are also present at lower silver/dendrimer molar ratios, while 2:1 and 
very low abundance 3:1 complexes emerge when the molar ratio is increased to greater than 1:1. Similar results were observed with PAMAMG1NH $\mathrm{N}_{2}$. These results agree with recent electrochemical studies of $\mathrm{Ag}^{+}$ binding to PAMAM dendrimers [32] that show 1:1 complexes are present when the silver to dendrimer molar ratio is $\leq 1$, while 2:1 complexes can form with an excess of $\mathrm{Ag}^{+}$. The fragmentation patterns of the $\mathrm{Ag}^{+} /$ dendrimer complexes are characterized by the loss of a dendrimer branch from the complex, with the silver ion remaining bound to a dendrimer fragment. The fragments lost upon dissociation of the $\mathrm{Ag}^{+} /$ PAMAMG2OH complexes suggest that the silver ions bind to the interior tertiary amines. Upon reduction of solutions containing $\mathrm{Ag}^{+} /$dendrimer complexes by hydrazine, complexes containing three silver atoms are observed for solutions containing PAMAMG1NH $\mathrm{N}_{2}$ while ions corresponding to complexes with four and five silver atoms are observed in the mass spectra of solutions containing PAMAMG2OH. The CAD spectra of the complexes formed after reduction of the silver ions further suggest the presence of a silver clusters because the ejection of all of the silver atoms occurs in a single CAD step, leaving the intact dendrimer.

\section{Acknowledgments}

The authors thank Dr. Allen J. Bard and Dr. Fu-Ren F. Fan for providing dendrimer samples, helpful discussions, and reviewing the manuscript. Dr. Mehdi Moini and Charles Cartwright are also recognized for providing assistance with the high-resolution mass spectrometry experiments. The authors gratefully acknowledge funding from the Welch Foundation (F1155) and the National Science Foundation (CHE-0315337).

\section{References}

1. Bosman, A. W.; Janssen, H. M.; Meijer, E. W. About Dendrimers: Structure, Physical Properties, and Applications. Chem. Rev. 1999, 99, 1665-1688.

2. Zeng, F. W.; Zimmerman, S. C. Dendrimers in Supramolecular Chemistry: From Molecular Recognition to Self-Assembly. Chem. Rev. 1997, 97, 1681-1712.

3. Crooks, R. M.; Zhao, M.; Sun, L.; Chechik, V.; Yeung, L. K. DendrimerEncapsulated Metal Nanoparticles: Synthesis, Characterization, and Applications to Catalysis. Acc. Chem. Res. 2001, 34, 181-190.

4. Baars, M. W. P. L.; Meijer. E. W. Host-Guest Chemistry of Dendritic Molecules. Top. Curr. Chem. 2001, 210, 131-182.

5. Tomalia, D. A.; Baker, H.; Dewald, J.; Hall, M.; Kallos, G.; Martin, S.; Roeck, J.; Ryder, J.; Smith, P. A New Class of Polymers-StarburstDendritic Macromolecules. Polym. J. 1985, 17, 117-132.

6. Tomalia, D. A.; Baker, H.; Dewald, J.; Hall, M.; Kallos, G.; Martin, S.; Roeck, J.; Ryder, J.; Smith, P. Dendritic Macromolecules-Synthesis of Starburst Dendrimers. Macromolecules 1986, 19, 2466-2468.

7. Zhao, M. Q.; Sun, L.; Crooks, R. M. Preparation of Cu Nanoclusters Within Dendrimer Templates. I. Am. Chem. Soc. 1998, 120, 4877-4878.

8. Zhao, M. Q.; Crooks, R. M. Intradendrimer Exchange of Metal Nanoparticles. Chem. Mater. 1999, 11, 3379-3385.

9. Zhao, M. Q.; Crooks, R. M. Dendrimer-Encapsulated Pt Nanoparticles: Synthesis, Characterization, and Applications to Catalysis. Adv. Mater. 1999, 11, 217-220.

10. Zhao, M. Q.; Crooks, R. M.Homogeneous Hydrogenation Catalysis with Monodisperse, Dendrimer-Encapsulated Pd and Pt Nanoparticles. Angew. Chem. Int. Ed. 1999, 38, 364-366.
11. Grohn, F.; Bauer, B. J.; Akpalu, Y. A.; Jackson, C. L.; Amis, E. J. Dendrimer Templates for the Formation of Gold Nanoclusters. Macromolecules 2000, 33, 6042-6050.

12. Crooks, R. M.; Lemon, B. I.; Sun, L.; Yeung, L. K.; Zhao, M. Q. Dendrimer Encapsulated Metals and Seminconductors: Synthesis, Characterization, and Applications. In Dendrimers III: Design, Dimension, Function, Vogtle, F., Ed.; Springer-Verlag: Berlin, 2001; pp 81-135.

13. McLuckey, S. A.; Asano, K. G.; Schaaff, T. G.; Stephenson, J. L. Ion Trap Collisional Activation of Protonated Poly(propylene imine) Dendrimers: Generations 1-5. Int. J. Mass Spectrom. 2000, 196, 419-437.

14. Weener, J. W.; van Dongen, J. L. J.; Meijer, E. W. Electrospray Mass Spectrometry Studies of Poly(propylene imine) Dendrimers: Probing Reactivity in the Gas Phase. J. Am. Chem. Soc. 1999, 121, 10346-10355.

15. Adhiya, A.; Wesdemiotis, C. Poly(propylene imine) Dendrimer Conformations in the Gas Phase: A Tandem Mass Spectrometry Study. Int. J. Mass Spectrom. 2002, 214, 75-88.

16. van der Wal, S.; Mengerink, Y.; Brackman, J. C.; de Brabander, E. M. M.; Jeronimus-Stratingh, C. M.; Bruins, A. P. Compositional Analysis of Nitrile Terminated Poly(propylene imine) Dendrimers by High-Performance Liquid Chromatography Combined with Electrospray Mass Spectrometry. J. Chromatogr. A. 1998, 825, 135-147.

17. Hummelen, J. C.; vanDongen, J. L. J.; Meijer, E. W. Electrospray Mass Spectrometry of Poly(propylene imine) Dendrimers-The Issue of Dendritic Purity or Polydispersity. Chem. Eur. J. 1997, 3, 1489-1493.

18. Blais, J. C.; Turrin, C. O.; Caminade, A. M.; Majoral, J. P. MALDI TOF Mass Spectrometry for the Characterization of Phosphorus-Containing Dendrimers. Scope and Limitations. Anal. Chem. 2000, 72, 5097-5105.

19. Sahota, H. S.; Lloyd, P. M.; Yeates, S. G.; Derrick, P. J.; Taylor, P. C.; Haddleton, D. M. Characterization of Aromatic Polyester Dendrimers by Matrix-Assisted Laser-Desorption Ionization Mass-Spectrometry. Chem. Commun. 1994, 19, 2445-2446.

20. Mowat, I. A.; Donovan, R. J.; Bruce, M.; Feast, W. J.; Stainton, N. M. Matrix Assisted Laser Desorption/Ionization Mass Spectrometry of Aryl Ester Dendrimers. Eur. J. Mass Spectrom. 1998, 4, 451-458.

21. Neubert, H.; Knights, K. A.; de Miguel, Y. R.; Cowan, D. A. MALDI TOF Post-Source Decay Investigation of Alkali Metal Adducts of Apolar Polypentylresorcinol Dendrimers. Macromolecules 2003, 36, 8297-8303.

22. Zhao, Z. W.; Xiong, S. X.; Liu, X. W.; Xin, B.; Wang, G. H. MatrixAssisted Laser Desorption/Ionization Time-of-Flight Mass Spectrometry Studies of Low Molecular Weight Dendrimers. Eur. J. Mass Spectrom. 2003, 9, 203-211.

23. Mazzaglia, A.; Scolaro, L. M.; Garozzo, D.; Malvagna, P.; Romeo, R. Synthesis and Characterization of Poly(amidoamine)-Platinum(II) Complexes. Detailed Speciation by Matrix-Assisted Laser Desorption Ionization Mass Spectrometry. J. Organomet. Chem. 2005, 690, 1978-1985.

24. Berndt, U. E. C.; Zhou, T.; Hider, R. C.; Liu, Z. D.; Neubert, H. Structural Characterization of Chelator-Terminated Dendrimers and Their Synthetic Intermediates by Mass Spectrometry. J. Mass Spectrom. 2005, 40, 1203-1214.

25. Hobson, L. J.; Feast, W. J. Poly(amidoamine) Hyperbranched Systems: Synthesis, Structure, and Characterization. Polymer 1999, 40, 1279-1297.

26. Kallos, G. J.; Tomalia, D. A.; Hedstrand, D. M.; Lewis, S.; Zhou, J. Molecular-Weight Determination of a Polyamidoamine Starburst Polymer by Electrospray Ionization Mass-Spectrometry. Rapid Commun. Mass Spectrom. 1991, 5, 383-386.

27. Schwartz, B. L.; Rockwood, A. L.; Smith, R. D.; Tomalia, D. A.; Spindler, R. Detection of High Molecular Weight Starburst Dendrimers by Electrospray Ionization Mass Spectrometry. Rapid Commun. Mass Spectrom. 1995, 9, 1552-1555.

28. Tolic, L. P.; Anderson, G. A.; Smith, R. D.; Brothers, H. M.; Spindler, R.; Tomalia, D. A. Electrospray Ionization Fourier Transform Ion Cyclotron Resonance Mass Spectrometric Characterization of High Molecular Mass Starburst (TM) Dendrimers. Int. J. Mass Spectrom. 1997, 165, 405-418.

29. He, M.; McLuckey, S. A. Tandem Mass Spectrometry of Half-Generation PAMAM Dendrimer Anions. Rapid Commun. Mass Spectrom. 2004, 18, 960-972.

30. Zhou, L.; Russell, D. H.; Zhao, M. Q.; Crooks, R. M. Characterization of Poly(amidoamine) Dendrimers and their Complexes with $\mathrm{Cu}^{2+}$ by Matrix-Assisted Laser Desorption Ionization Mass Spectrometry. Macromolecules 2001, 34, 3567-3573.

31. Peterson, J.; Allikmaa, V.; Subbi, J.; Pehk, T.; Lopp, M. Structural Deviations in Poly(amidoamine) Dendrimers: A MALDI-TOF MS Analysis. Eur. Polym. J. 2003, 39, 33-42.

32. Fan, F. R. F.; Mazzitelli, C. L.; Brodbelt, J. S.; Bard, A. J. Electrochemical, Spectroscopic, and Mass Spectrometric Studies of the Interaction of Silver Species with Polyamidoamine Dendrimers. Anal. Chem. 2005, 77, 4413-4422.

33. Peterson, J.; Allikmaa, V.; Pehk, T.; Lopp, M. Fragmentation of PAMAM Dendrimers in Methanol. Proc. Estonian Acad. Sci. Chem. 2001, 50, 167-172. 